\title{
Algal symbionts increase oxidative damage and death in coral larvae at high temperatures
}

\author{
Irina M. Yakovleva ${ }^{1,2}$, Andrew H. Baird ${ }^{3, *}$, Hiromi H. Yamamoto ${ }^{4}$, \\ Ranjeet Bhagooli $^{1,5,6}$, Masanori Nonaka ${ }^{4}$, Michio Hidaka ${ }^{1}$ \\ ${ }^{1}$ Department of Chemistry, Biology and Marine Science, University of the Ryukyus, Nishihara, Okinawa 903-0213, Japan \\ ${ }^{2}$ A.V. Zhirmunsky Institute of Marine Biology, Far East Branch of the Russian Academy of Sciences, Palchevskogo, 17, \\ Vladivostok 690041, Russia \\ ${ }^{3}$ ARC Centre of Excellence for Coral Reef Studies, James Cook University, Townsville, Queensland 4811, Australia \\ ${ }^{4}$ Churaumi Aquarium, Motobu-cho, Okinawa 905-0206, Japan \\ ${ }^{5}$ Department of Biosciences, Faculty of Science, University of Mauritius, Reduit, Mauritius \\ ${ }^{6}$ The Biodiversity and Environment Institute, Reduit, Mauritius
}

\begin{abstract}
Mutualisms are often viewed as reciprocal exploitations that nonetheless provide net benefits to each partner. While the benefits of symbiosis with dinoflagellates of the genus Symbiodinium (zooxanthellae) for corals are well understood, the costs of the association, particularly when under stress, remain a focus of much research. One of the primary impediments to exploring the costs of symbiosis in zooxanthellate corals is that it is impossible to examine the animal host in isolation. Evidence for a cost of symbiosis with zooxanthellae includes the fact that direct transmission of zooxanthellae between generations is rare, particularly in broadcast spawning corals. Fortuitously, the absence of zooxanthellae in oocytes of many species and the ability to readily infect larvae with zooxanthellae provide an opportunity to compare individuals with and without these symbionts. Here, we use this larval model to show that individuals with zooxanthellae have lower survival than those lacking zooxanthellae when exposed to high temperature. Higher activity of anti-oxidant defenses and higher levels of oxidative cellular damage in larvae with zooxanthellae suggest that oxidative stress originating in the symbionts is a cause of tissue damage in the host under heat stress. We hypothesize that this may be one reason for the absence of direct transmission of zooxanthellae in most broadcast spawning corals whose propagules must spend at least $1 \mathrm{~d}$ on the ocean surface.
\end{abstract}

KEY WORDS: Bleaching $\cdot$ Coral reef $\cdot$ Evolution $\cdot$ Oxidative stress $\cdot$ Symbiosis

\section{INTRODUCTION}

Symbiosis between corals and Symbiodinium sp. (zooxanthellae) is dependent upon the mutual exchange of nutrients, with the coral host receiving $30 \%$ of its total nitrogen and $90 \%$ of its carbon needs from the symbionts in exchange for nitrogen and phosphorus, which the host provides for the alga (see review by Yellowlees et al. 2008). The association is beneficial to the coral host because it gains an additional metabolic capability, allowing corals to expand into an otherwise inhospitable environment, the oli- gotrophic waters of the world tropical oceans (Douglas 1994). However, while the benefits of symbiosis with zooxanthellae for the coral host are reasonably well understood, the costs of the association, particularly under stress such as high temperatures, remain a focus of much research. For example, when exposed to high temperature and/or solar radiation, the photosynthetic apparatus of the zooxanthellae can be overwhelmed, producing a burden of oxygen radicals, some of which, such as hydrogen peroxide, can permeate through the cell wall of the symbiont (Dykens et al. 1992, Tchernov et al. 2004) and cause 
oxidative stress and tissue damage in the host (Lesser \& Shick 1990, Lesser et al. 1990).

Two distinct modes of symbiont acquisition exist: vertical transmission, whereby symbionts are passed directly from the parent to offspring (typically in the oocytes), and horizontal transmission whereby symbionts must be acquired anew from the environment in each generation. The vast majority of zooxanthellate scleractinian corals have horizontal transmission; only 4 of approximately 85 genera of broadcast spawning corals have vertical transmission (Baird et al. 2009), suggesting either substantial costs or strong evolutionary constraints associated with symbionts in the oocytes (Genkai-Kato \& Yamamura 1999, Knowlton \& Rohwer 2003). In contrast, only 1 of 33 genera that brood has horizontal transmission (Baird et al. 2009). The presence of maternally derived symbionts might be disadvantageous in broadcast spawned coral propagules, which are typically positively buoyant (Arai et al. 1993) and can take between 12 to $72 \mathrm{~h}$ to become motile (Baird et al. 2009). Consequently, these propagules may spend many hours on the surface of the ocean under conditions of high solar radiation (Gleason \& Wellington 1995, Gleason et al. 2006) and fluctuating temperatures (Wick et al. 1996), both of which represent a stress for photosynthesis, as described above. In contrast, the propagules of brooding corals are capable of swimming on release, or shortly afterwards (Fadlallah 1983), and therefore can avoid the ocean surface.

Fortuitously, the absence of zooxanthellae in oocytes of most broadcast spawning corals provides an opportunity to manipulate symbioses because larvae can be readily infected with heterogeneous zooxanthellae under experimental conditions (van Oppen 2001, Weis et al. 2001). Consequently, it is possible to compare symbiotic and non-symbiotic individuals of the same species, and to manipulate the identity of the holobiont (the host and symbiont as a unit) to explore the role of both partners in determining the response to stress. Control over the make-up of the association is not possible in adults because even completely bleached adults still contain residual densities of zooxanthellae (Jones 2008), and it is not possible to infect adults with novel strains of zooxanthellae (Hoegh-Guldberg et al. 2002; but see Lewis \& Coffroth 2004). Other features of coral larvae that make them ideal for manipulative experiments include the fact that they do not need to feed (Fadlallah 1983), plus they have an extraordinary capacity to delay metamorphosis (Graham et al. 2008), and therefore, can be maintained easily for long periods in culture. In addition, coral larvae are small, seasonally abundant and easy to handle, allowing comparisons among many individuals for statistical power. This model system has extraordinary versatility and promises to provide novel insights into our understanding of symbiotic associations in general and corals in particular.

To explore the costs of symbiosis in corals, we compared survival, antioxidant activity and cellular damage in zooxanthellate and non- zooxanthellate larvae of the broadcast spawning coral Acropora intermedia under ambient $\left(26^{\circ} \mathrm{C}\right)$ and high $\left(32^{\circ} \mathrm{C}\right)$ temperature. Our results clearly demonstrate that zooxanthellae reduce the capacity of coral larvae to cope with environmental stresses typically experienced early in their life history, and we hypothesize that this cost may partially explain why vertical transmission of symbionts is rare in broadcast spawning corals.

\section{MATERIALS AND METHODS}

Larval culture and maintenance. The gametes of 6 colonies of the broadcast spawning coral Acropora intermedia were collected from colonies maintained at the Okinawa Churaumi Aquarium, Japan in June 2003. Egg sperm bundles from each colony were mixed in a single bulk cross to ensure adequate cross-fertilization, and larvae were cultured following Babcock et al. (2003). On completion of embryogenesis, larvae from the bulk cross were placed in 6 glass jars (2 l) in $0.45 \mu \mathrm{m}$ filtered seawater (FSW) at initial densities of approximately 1000 larvae $1^{-1}$. In order to produce symbiotic larvae for the experiment, zooxanthellae were freshly isolated from numerous branches of single adult colony of $A$. intermedia (following Baird et al. 2006) and added to 3 of 6 glass jars at densities of approximately $1 \times$ $10^{6} \mathrm{ml}^{-1}$ within $30 \mathrm{~min}$ of preparation. Zooxanthellate isolates were identified as belonging to clade type C3 via denaturing gradient gel electrophoresis (DGGE) analysis of the internal transcribed spacer 2 (ITS2) region following LaJeunesse (2002). Both symbiotic and non-symbiotic larval cultures were maintained in the laboratory for $6 \mathrm{~d}$ following spawning under a photon irradiance of $160 \mu \mathrm{mol} \mathrm{m}{ }^{-2} \mathrm{~s}^{-1}$ with a $12: 12 \mathrm{~h}$ light:dark photoperiod at temperatures between 25 and $27^{\circ} \mathrm{C}$. This photon irradiance was slightly greater than that needed to saturate photosynthesis of in hospite zooxanthellae of $A$. intermedia at $2 \mathrm{~m}$ depth at the collection site, $\left(I_{\mathrm{k}}=157 \mu \mathrm{mol}\right.$ photons $\left.\mathrm{m}^{-2} \mathrm{~s}^{-1}\right)$. Photon irradiance was measured using a LI-250 quanta meter (LICOR). Water was changed in both symbiotic and non-symbiotic cultures every other day. Inoculation with zooxanthellae was repeated on every FSW change. The cultures remained healthy throughout the incubation period; no larvae settled and all were actively swimming. The average number of zooxanthellae per infected larva on introduction into experimental treatments was $17.3 \pm$ $5.2($ mean $\pm \mathrm{SD}, \mathrm{n}=150)$. 
Experimental design and analysis. To test the effect of the presence of zooxanthellae on survival of Acropora intermedia larvae exposed to high temperature, 4 treatment groups were used: (1) $26^{\circ} \mathrm{C}$ non-symbiotic larvae; (2) $26^{\circ} \mathrm{C}$ symbiotic larvae; (3) $32^{\circ} \mathrm{C}$ non-symbiotic larvae; (4) $32^{\circ} \mathrm{C}$ symbiotic larvae. Six replicate $250 \mathrm{ml}$ glass bowls each containing 400 to 600 larvae were used in each group; 3 bowls were used to estimate larval survival and 3 as replicates for the bioassays. Treatment duration was $3 \mathrm{~d}$. Temperatures were maintained using temperature control units (EYELA, Thermister Tempet T-80), and larvae were kept under $160 \mu \mathrm{mol}$ photons $\mathrm{m}^{-2} \mathrm{~s}^{-1}$ of photosynthetically active radiation (PAR) with a 12:12 h light:dark photoperiod. PAR was supplied by cool-white fluorescent light tubes with an emission spectrum similar to that of sunlight at wavelengths between 400 and $720 \mathrm{~nm}$.

Larval survival, levels of oxidative stress (measured by the activity of the antioxidant enzyme superoxide dismutase: SOD), and the level of oxidative damage (measured by the content of malondialdehyde: MDA, a product of lipid peroxidation) were examined daily during the experimental period. In addition, because some mycosporine-like amino acids (MAAs) scavenge reactive oxygen species, providing rapid protection against oxidative stress before antioxidant enzymes are induced (Oren \& Gunde-Cimerman 2007), the abundance of MAAs in Acropora intermedia larvae was also measured daily. Survival of symbiotic and non-symbiotic larvae was determined by counting the number of larvae alive in each replicate bowl $(n=3)$ in each treatment daily. Coral larvae lyse shortly after death and disappear from cultures and, therefore, it was not necessary to distinguish dead larvae from live larvae; if larvae were present, they were assumed to be alive. For the bioassays and MAA analysis, 70 to 150 symbiotic or non-symbiotic larvae were pipetted from the replicate bowls ( $\mathrm{n}=3$ per treatment), rinsed in $0.2 \mu \mathrm{m} \mathrm{FSW}$, drained of excess seawater, then frozen in liquid $\mathrm{N}_{2}$ and stored at $-80^{\circ} \mathrm{C}$.

Analyses of SOD activity and MDA content. For the bioassays, larvae were crushed in liquid nitrogen and homogenized in ice-cold $50 \mathrm{mM}$ potassium phosphate buffer ( $\mathrm{pH}$ 7.8) containing protease inhibitor cocktail (Sigma cat. No. P8340). Extracts were sonicated for $30 \mathrm{~min}$ on ice and centrifuged at $14000 \times g$ for $5 \mathrm{~min}$ at $3^{\circ} \mathrm{C}$. The resulting supernatants were used for analysis of total protein content following Bradford (1976), and for assay of SOD activity and MDA content.

The activity of total SOD was assayed spectrophotometrically following Yakovleva et al. (2004). Standards were prepared from bovine erythrocyte SOD (Wako Chemicals cat. No. 190-08771). SOD was expressed as units $(\mathrm{U})$ of enzyme activity per unit of protein mass $\left(\mathrm{U} \cdot \mathrm{mg}\right.$ protein $\left.^{-1}\right)$.
The content of MDA was determined as thiobarbituric acid (TBA) reactive metabolites (Kamal et al. 1989). The larval sample (500 $\mu$ l) was extracted with $1 \mathrm{ml} 0.67 \%$ TBA in $20 \%$ trichloroacetic acid. The mixture was incubated in a water bath at $90^{\circ} \mathrm{C}$ for $45 \mathrm{~min}$ and then quickly cooled on ice. After cooling, the sample was extracted with $4 \mathrm{ml} n$-butanol, homogenized for $5 \mathrm{~min}$, and centrifuged at $20000 \times g$ for $10 \mathrm{~min}$; the absorbance of supernatant was measured at $535 \mathrm{~nm}$. Concentrations of MDA were calculated using an extinction coefficient of $156 \mathrm{M} \mathrm{cm}^{-1}$ at $535 \mathrm{~nm}$ after subtraction of the absorbance at $535 \mathrm{~nm}$ of a blank without addition of larval material. The level of lipid peroxidation was expressed as $\mathrm{nmol} \cdot \mathrm{mg}$ protein ${ }^{-1}$.

Analysis of MAAs. Extraction and analysis of MAAs in larval samples followed a slightly modified procedure of Yakovleva \& Baird (2005). MAAs were separated by reverse-phase isocratic HPLC on a Nucleosil $100 \mathrm{C} 8$ column $(25 \mathrm{~cm}, 4.6 \mu \mathrm{m})$ protected with a Nucleosil C8 guard (4.6 mm i.d. $\times 10 \mathrm{~mm}$ length) filled with the same material in an aqueous mobile phase of $0.1 \%$ acetic acid and $40 \%$ methanol. The flow rate was

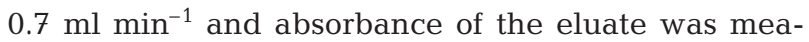
sured online at 313 and $330 \mathrm{~nm}$. The MAA concentration in each sample was normalized to the number of extracted larvae.

Statistical analysis. A 3-way factorial ANOVA was used to test for difference in the means of the response variables: (1) proportion of larvae alive (i.e. survival), (2) units of SOD activity, (3) MDA content and (4) the abundance of 6 MAAs: mycosporine-glycine, shinorine, porphyra-334, mycosporine-2glycine, palythine and asterina-330. Factors were (1) symbiont status (2 levels: symbiotic and non-symbiotic), (2) temperature ( 2 levels: 26 and $32^{\circ} \mathrm{C}$ ) and (3) exposure time (4 levels: $0,1,2$ and $3 \mathrm{~d}$ ). All factors were treated as fixed. Raw values of all variables were used after an examination of the residuals revealed no major bias in the models. Linear regression was used to determine how well mean SOD activity, MDA content and mycosporineglycine content predicted mean larval survival $(n=12)$.

\section{RESULTS}

Larval survival depended on the interactive effects of duration of exposure, symbiotic status and temperature (3-way interaction: $F_{3,32}=6.81, \mathrm{p}=0.001$ ) (Fig. 1A). At $26^{\circ} \mathrm{C}$, larval survival was very high $(>99 \%)$ and did not vary significantly with length of exposure or symbiotic status (Fig. 1A). In contrast, after $3 \mathrm{~d}$ exposure at $32^{\circ} \mathrm{C}$, survival of both symbiotic and non-symbiotic larvae was significantly lower than at $26^{\circ} \mathrm{C}$, and symbiotic larvae showed higher susceptibil- 

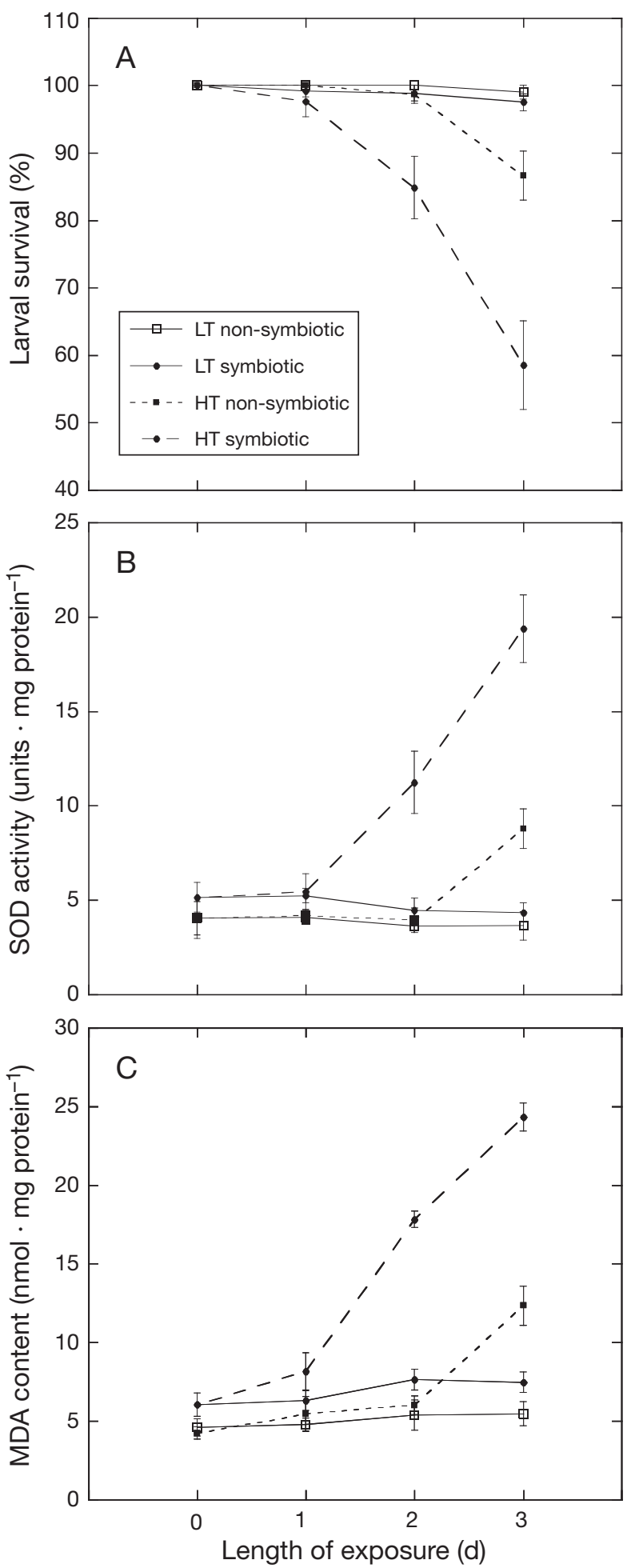

Fig. 1. Acropora intermedia. The effect of symbiotic state (non-symbiotic and symbiotic) and temperature (LT $=26^{\circ}$ and $\mathrm{HT}=32^{\circ} \mathrm{C}$ ) on (A) larval survival, (B) activity of the antioxidant enzyme, superoxide dismutase (SOD), and (C) content of the lipid peroxidation product, malondialdehyde (MDA), in the larval tissue over $3 \mathrm{~d}$ of exposure. Means \pm SE $(n=3)$ are shown. For a detailed description of treatments, see 'Materials and methods; Experimental design and analysis' ity (60\% survival after 3 d versus $90 \%$ ) and responded earlier (i.e. on day 2 versus day 3 ) to high temperature than non-symbiotic larvae (Fig. 1A).

Activity of the antioxidant enzyme SOD also varied with the interactive effects of duration of exposure, symbiotic status and temperature (3-way interaction: $F_{3,32}=17.14, \mathrm{p}<0.001$ ) (Fig. $1 \mathrm{~B}$ ). At $26^{\circ} \mathrm{C}$, mean SOD activity of larvae did not differ with either duration of exposure or symbiotic status (Fig. 1B). At $32^{\circ} \mathrm{C}$, SOD activity was consistently higher in symbiotic larvae and increased through time (Fig. 1B). After $3 \mathrm{~d}$ exposure, SOD activity in symbiotic larvae was more than double that in non-symbiotic larvae. In addition, high temperature affected SOD activity in the non-symbiotic larvae, but not before $3 \mathrm{~d}$ exposure, when activity was twice that of non-symbiotic larvae at $26^{\circ} \mathrm{C}$. The level of lipid peroxidation, expressed as mean MDA content, also varied with interactive effects of duration of exposure, symbiotic status and temperature (3-way interaction: $F_{3,32}=10.98, \mathrm{p}<0.001$ ) and displayed a pattern similar to the SOD results discussed above (Fig. 1C).

Temperature did not affect the abundance of any of the MAAs, with the exception of mycosporine-glycine (Myc-Gly) (Fig. 2). Myc-Gly abundance varied with interactive effects of temperature, symbiont status and exposure (Fig. 2D; 3-way interaction, $F_{3,32}=9.52$, $\mathrm{p}<$ 0.001). High temperature caused a pronounced decline in the abundance of Myc-Gly in both nonsymbiotic and symbiotic larvae (Fig. 2D); however, the decline was much greater in symbiotic larvae, in which (after $3 \mathrm{~d}$ ) the Myc-Gly pool was almost depleted, as opposed to a $70 \%$ decrease in nonsymbiotic larvae (Fig. 2D). Unlike the patterns of decline in SOD (Fig. 1B) and MDA (Fig. 1C), there was no time delay in the decline of Myc-Gly. Palythine (Fig. 2A $F_{1,32}=189.71, \mathrm{p}<0.001$ ), porphyra-334 (Fig. $2 \mathrm{~B} ; F_{1,32}=6.795, \mathrm{p}=0.014$ ) and mycosporine2glycine (Fig. 2E; $F_{1,32}=6.845, \mathrm{p}=0.013$ ) were all initially higher in symbiotic larvae; however, after $3 \mathrm{~d}$ exposure this difference was no longer apparent in porphyra-334 and mycosporine-2glycine. Shinorine declined with time but did not vary with symbiont status (Fig. $2 C_{i} F_{3,32}=3.357, p=0.031$ ). Asterine-330 did not vary with any factor (Fig. $2 F$ ).

\section{DISCUSSION}

We show here that coral larvae containing zooxanthellae had higher expression of anti-oxidant defenses in terms of increases in superoxide dismutase (SOD) activities and depletion of the mycosporine-glycine (Myc-Gly) pool, higher oxidative cellular damage (as indicated by increases in the content of malondialde- 


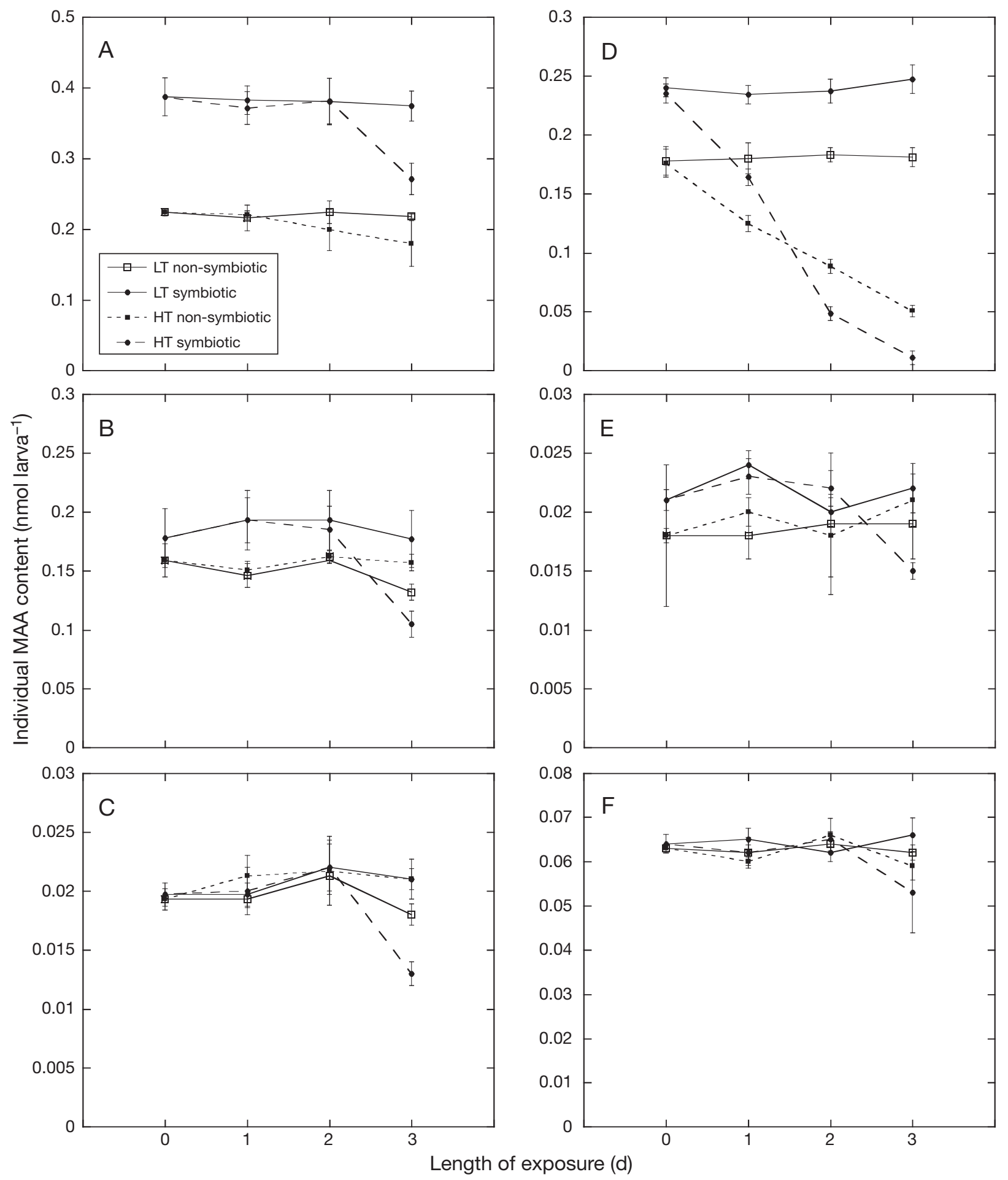

Fig. 2. Acropora intermedia. The effect of symbiotic state (non-symbiotic and symbiotic) and temperature $\left(\mathrm{LT}=26^{\circ} \mathrm{C}\right.$ and $\mathrm{HT}=$ $32^{\circ} \mathrm{C}$ ) on larval content of individual mycosporine-like amino acids (MAAs): (A) palythine, (B) porphyra-334, (C) shinorine, (D) mycosporine-glycine, (E) mycosporine-2glycine and (F) asterina-330, all over $3 \mathrm{~d}$ of exposure. Means $\pm \mathrm{SE}(\mathrm{n}=3$ ) are shown. For a detailed description of treatments see 'Materials and methods; Experimental design and analysis'

hyde, MDA), and lower survival than larvae lacking zooxanthellae when exposed to thermal stress. The correlation between SOD activity and larval survival is striking; mean SOD abundance explained $97.6 \%$ of the variation in mean larval survival $\left(F_{1,13}=489.1 ; \mathrm{p}<\right.$ 0.001). Larvae with zooxanthellae appear to be ex- 
posed to an additional source of oxidative stress originating within the symbiotic algae, most probably as a result of reactive oxygen species produced during the breakdown of photosynthesis at high temperatures.

Under ambient conditions, the larvae of Acropora intermedia have very high survival, irrespective of the presence or absence of zooxanthellae (Fig. 1A), with no signs of oxidative stress or cellular damage during the experimental period (Fig. 1B,C). Symbionts do not appear to be a burden for larvae in the absence of temperature stress (Ben-David-Zaslow \& Benayahu 1998). In contrast, the presence of zooxanthellae significantly affects survival of A. intermedia larvae exposed to thermal stress (Fig 1A). Although larval survival is often low at high temperature (Bassim \& Sammarco 2003, Nozawa \& Harrison 2007), the rate of mortality in symbiotic larvae was higher and more rapid than in non-symbiotic larvae, suggesting that symbionts are a severe burden to coral larvae under heat stress (Fig. 1A).

Another stress known to differentially affect symbiotic individuals is ultraviolet radiation (UVR), which reduces larval survival in species with zooxanthellae (Gleason \& Wellington 1995) to a much greater extent than in species lacking zooxanthellae (Wellington \& Fitt 2003). In addition, symbiont-free coral recruits survive better than symbiont-containing recruits of other species when exposed to the herbicide diuron (Negri et al. 2005). Furthermore, high intensity of photosynthetically active radiation (PAR) and sudden increases in temperature cause planulae of Stylophora pistillata to expel symbionts through their oral poles (Rinkevich \& Loya 1979). Thus, many types of stress, including UVR, high visible light, pollution and temperature may cause zooxanthellae to be a burden early in the life history of corals.

The difference in susceptibility to high temperature is highly correlated with differences in oxidative stress in larvae. In adult cnidarians, the degree of bleaching and subsequent mortality after exposure to elevated temperature and UVR is directly related to the production of reactive oxygen species (ROS) and levels of oxidative stress (Lesser et al. 1990, Downs et al. 2002). The correlation between SOD activity and larval survival $\left(\mathrm{r}^{2}=0.967\right)$ suggests the following chain of events. A high flux of superoxide radicals damages tissue and causes mortality in both symbiotic and non-symbiotic larvae during exposure to elevated temperature (Halliwell \& Gutteridge 1999). However, symbiotic larvae exhibit significantly higher levels of oxidative damage than non-symbiotic counterparts (Fig. 1C), which is consistent with an increase in ROS production from symbiont photosynthesis under elevated temperatures (Dykens \& Shick 1982, Dykens 1984). Exposures to UVR and elevated temperatures induce high concentrations of superoxide radicals and hydrogen peroxide that cannot be scavenged by the activities of antioxidant enzymes in cultured zooxanthellae (Lesser 1996). ROS produced within the symbionts and translocated to the host tissue (Lesser \& Stochaj 1990) is a burden additional to the ROS generated independently within the host as a result of non-photosynthetic hyperoxia (Lesser 1996). Although these views were developed on the bases of experiments conducted on adults of cnidarian species, similar processes are likely in coral larvae and may affect their capacity to tolerate environmental stresses.

Interestingly, there was a delay of $24 \mathrm{~h}$ before symbiotic larvae began to die under high temperature (Fig. 1A). A similar delay in the onset of mortality is evident in symbiotic larvae of Acropora muricata at $32^{\circ} \mathrm{C}$ (Baird et al. 2006). In contrast, larvae of Porites astreoides respond rapidly to high temperature (30 to $33^{\circ} \mathrm{C}$ ) (Edmunds et al. 2005). The difference in response time is possibly a result of difference in the density of symbionts between taxa, viz. tens of symbionts per larva in Acropora intermedia in our study versus thousands in $P$. astreoides (Edmunds et al. 2005). In the present study, extremely low mortality after $1 \mathrm{~d}$ of exposure to high temperature is consistent with the lack of SOD induction and no change in MDA content in the larval tissue (Fig. 1B,C), indicating either that both symbiotic and non-symbiotic individuals were not stressed sufficiently to initiate the antioxidant enzyme system under these conditions, or that the rate of ROS formation was limited during this period or regulated by other biochemical defenses, such as small-molecule antioxidants.

A similar delay in the onset of oxidative stress under high temperature $\left(33^{\circ} \mathrm{C}\right)$ also occurs in adult scleractinian corals (Yakovleva et al. 2004). The smallmolecule antioxidant mycosporine-glycine (Myc-Gly) functions as first aid to oxidative stress before antioxidant enzymes are induced. In the present study, a pronounced reduction in the concentration of MycGly (Fig. 2D) (in contrast to stable levels of most other MAAs, Fig. 2A-C,E,F) occurs in both non-symbiotic and symbiotic larvae after $1 \mathrm{~d}$ exposure to temperature stress. Similarly, the MAA pool dominated by Myc-Gly decreases significantly in Atlantic cod exposed to UVR (Lesser et al. 2001). Thus, the delay in onset of oxidative stress and mortality suggests that larvae are initially protected against ROS-mediated effects of elevated temperature by free radical scavenging capacity of Myc-Gly in the tissue during the first $24 \mathrm{~h}$ of stress exposure. Furthermore, less pronounced depletion of the Myc-Gly pool in non-symbiotic larvae (Fig. 2D) suggests a lower flux of ROS in these individuals, which may partly explain the delay 
in the onset of oxidative stress and damage (the induction of SOD and the MDA increase) in non-symbiotic larvae until Day 2 of high temperature exposure (Fig. 1B,C).

Symbionts are clearly not always a burden to the host. Almost all species of scleractinian corals that enter symbiosis cannot exist without their symbionts and therefore under some conditions the benefits of symbiosis must outweigh the costs. Indeed, symbionts may even assist the host to combat oxidative stress. Examples of this assistance, documented in other systems, include host cells of the symbiotic demosponge Petrosia ficiformis (Regoli et al. 2000) and sea anemones (Richier et al. 2005), both of which have a greater capacity to cope with oxidative stress compared to those of their non-symbiotic counterparts, possibly due to acclimation to the high oxygen pressure produced by symbionts (Richier et al. 2005).

Higher mortality of symbiotic larvae at high temperature suggests that coral species with vertical transmission of symbionts may be more prone to global warming because mortality of propagules will be higher and therefore recruitment may be reduced. Further experiments using symbiotic and non-symbiotic larvae of other species of corals which include investigating settlement rates and survival of recruits under high temperature are required to verify this hypothesis. This is particularly critical since high coral mortality has followed a number of recent bleaching events (Baird \& Marshall 2002, Coles \& Brown 2003) and recruitment plays such an integral part in the replenishment of coral populations. Furthermore, the higher susceptibility of symbiotic larvae to temperature stress may partially explain why vertical transmission is absent in many species, particularly broadcast spawning corals in the genus Acropora that have positively buoyant gametes with an extended pre-motile period (Baird et al. 2009). Likewise, on parity with the worldwide high temperature anomalies, elevated UVR environments can also affect the population biology of corals that transmit algal symbionts vertically to offspring. Exposure to UVR appears to induce significantly higher mortality in symbiotic larvae of brooding corals (Gleason \& Wellington 1995) compared to nonsymbiotic larvae of broadcast-spawners (Wellington \& Fitt 2003). Future research should test whether conditions prevailing at the oceans surface (such as high PAR and UVR) are lethal to coral larvae that contain symbionts.

We conclude that dinoflagellate symbionts appear to increase oxidative stress and tissue damage in coral larvae under high temperature, thereby reducing larval survival. This suggests that zooxanthellae may be a costly burden early in the life history of some scleractinian corals.
Acknowlegements. This research was partly supported by a Grant-in-Aid for Scientific Research from the Japan Society for Promotion of Science (JSPS) to I.M.Y. and a short-term Scientific Fellowship from JSPS to A.H.B. We are grateful to the staff of Sesoko Station, Tropical Biosphere Research Center, University of the Ryukyus, Okinawa, Japan for use of facilities. A.H.B. thanks H. Yamasaki and K. Takayuki from the University of the Ryukyus and S. Uchida from the Okinawa Churaumi Aquarium for their support while in Japan. S. Connolly, M. Hoogenboom, A. Kerswell and M. van Oppen provided valuable advice on the manuscript.

\section{LITERATURE CITED}

Arai T, Kato M, Heyward A, Ikeda Y, Iizuka T, Maruyama T (1993) Lipid composition of positively buoyant eggs of reef building corals. Coral Reefs 12:71-75

Babcock RC, Baird AH, Piromvaragorn S, Thomson DP, Willis BL (2003) Identification of scleractinian coral recruits from Indo-Pacific reefs. Zool Stud 42:211-226

> Baird AH, Marshall PA (2002) Mortality, growth and reproduction in scleractinian corals following bleaching on the Great Barrier Reef. Mar Ecol Prog Ser 237:133-141

Baird AH, Gilmour JP, Kamiki T, Nonaka M, Pratchett MS, Yamamoto HH, Yamasaki H (2006) Temperature tolerance of symbiotic and non-symbiotic coral larvae. Proc 10th Int Coral Reef Symp, Okinawa, p 38-42

Baird AH, Guest JR, Willis BL (2009) Biogeographical and evolutionary patterns in the reproductive biology of scleractinian corals. Annu Rev Ecol Evol Syst 40: (in press)

Bassim KM, Sammarco PW (2003) Effects of temperature and ammonium on larval development and survivorship in a scleractinian coral (Diploria strigosa). Mar Biol 142: 241-252

Ben-David-Zaslow R, Benayahu Y (1998) Competence and longevity in planulae of several species of soft corals. Mar Ecol Prog Ser 163:235-243

Bradford MM (1976) A rapid and sensitive method for the quantification of microgram quantities of protein utilizing the principle of protein-dye binding. Anal Biochem 72: 248-254

Coles SL, Brown BE (2003) Coral bleaching - capacity for acclimatization and adaptation. Adv Mar Biol 46:183-223

Douglas AE (1994) Symbiotic interactions. Oxford University Press, New York

Downs CA, Fauth JE, Halas JC, Dustan P, Bemiss J, Woodley CM (2002) Oxidative stress and seasonal coral bleaching. Free Radic Biol Med 33:533-543

Dykens JA (1984) Enzymatic defences against oxygen toxicity in marine cnidarians containing endosymbiotic algae. Mar Biol Lett 5:291-301

Dykens JA, Shick JM (1982) Oxygen production by endosymbiotic algae controls superoxide-dismutase activity in their animal host. Nature 297:579-580

Dykens JA, Shick JM, Benoit C, Buettner GR, Winston GW (1992) Oxygen radical production in the sea-anemone Anthopleura elegantissima and its endosymbiotic algae. J Exp Biol 168:219-241

Edmunds PJ, Gates RD, Leggat W, Hoegh-Guldberg O, Allen-Requa L (2005) The effect of temperature on the size and population density of dinoflagellates in larvae of the reef coral Porites astreoides. Invertebr Biol 124: 185-193

Fadlallah YH (1983) Sexual reproduction, development and larval biology in scleractinian corals: a review. Coral Reefs $2: 129-150$ 
Genkai-Kato M, Yamamura N (1999) Evolution of mutualistic symbiosis without vertical transmission. Theor Popul Biol 55:309-323

Gleason DF, Wellington GM (1995) Variation in UVB sensitivity of planula larvae of the coral Agaricia agaricites along a depth gradient. Mar Biol 123:693-703

Gleason DF, Edmunds PJ, Gates RD (2006) Ultraviolet radiation effects on the behavior and recruitment of larvae from the reef coral Porites astreoides. Mar Biol 148:503-512

Graham ER, Baird AH, Connolly SR (2008) Survival dynamics of scleractinian coral larvae and implications for dispersal. Coral Reefs 27:529-539

Halliwell B, Gutteridge JMC (1999) Free radicals in biology and medicine. Oxford Science Publishers, Oxford

Hoegh-Guldberg O, Jones RJ, Ward S, Loh WK (2002) Is coral bleaching really adaptive? Nature 415:601-602

Jones RJ (2008) Coral bleaching, bleaching-induced mortality, and the adaptive significance of the bleaching response. Mar Biol 154:65-80

Kamal AM, Gomaa A, Khafif M, Hammad A (1989) Plasma lipid peroxides among workers exposed to silica or asbestos dusts. Environ Res 49:173-180

Knowlton N, Rohwer F (2003) Multispecies microbial mutualisms on coral reefs: the host as a habitat. Am Nat 162: S51-S62

LaJeunesse TC (2002) Diversity and community structure of symbiotic dinoflagellates from Caribbean coral reefs. Mar Biol 141:387-400

Lesser M (1996) Elevated temperatures and ultraviolet radiation cause oxidative stress and inhibit photosynthesis in symbiotic dinoflagellates. Limnol Oceanogr 41:271-283

> Lesser MP, Shick JM (1990) Effects of visible and ultravioletradiation on the ultrastructure of zooxanthellae (Symbiodinium sp.) in culture and in situ. Cell Tissue Res 261: 501-508

> Lesser MP, Stochaj WR (1990) Photoadaptation and protection against active forms of oxygen in the symbiotic prokaryote Prochloron sp. and its ascidian host. Appl Environ Microbiol 56:1530-1535

Lesser MP, Stochaj WR, Tapley DW, Shick JM (1990) Bleaching in coral-reef anthozoans: effects of irradiance, ultraviolet-radiation, and temperature on the activities of protective enzymes against active oxygen. Coral Reefs 8: $225-232$

Lesser MP, Farrell JH, Walker CW (2001) Oxidative stress, DNA damage and p53 expression in the larvae of Atlantic cod (Gadus morhua) exposed to ultraviolet (290-400 nm) radiation. J Exp Biol 204:157-164

Lewis CL, Coffroth MA (2004) The acquisition of exogenous algal symbionts by an octocoral after bleaching. Science 304:1490-1492

Editorial responsibility: Otto Kinne, Oldendorf/Luhe, Germany
Negri A, Vollhardt C, Humphrey C, Heyward A, Jones R, Eaglesham G, Fabricius K (2005) Effects of the herbicide diuron on the early life history stages of coral. Mar Pollut Bull 51:370-383

Nozawa Y, Harrison PL (2007) Effects of elevated temperature on larval settlement and post-settlement survival in scleractinian corals, Acropora solitaryensis and Favites chinensis. Mar Biol 152:1181-1185

Oren A, Gunde-Cimerman N (2007) Mycosporines and mycosporine-like amino acids: UV protectants or multipurpose secondary metabolites? FEMS Microbiol Lett 269:1-10

> Regoli F, Cerrano C, Chierici E, Bompadre S, Bavestrello G (2000) Susceptibility to oxidative stress of the Mediterranean demosponge Petrosia ficiformis: role of endosymbionts and solar irradiance. Mar Biol 137:453-461

> Richier S, Furla P, Plantivaux A, Merle PL, Allemand D (2005) Symbiosis-induced adaptation to oxidative stress. J Exp Biol 208:277-285

Rinkevich B, Loya Y (1979) The reproduction of the Red Sea coral Stylophora pistillata. 1. Gonads and planulae. Mar Ecol Prog Ser 1:133-144

> Tchernov D, Gorbunov MY, de Vargas C, Yadav SN, Milligan AJ, Haggblom M, Falkowski PG (2004) Membrane lipids of symbiotic algae are diagnostic of sensitivity to thermal bleaching in corals. Proc Natl Acad Sci USA 101: 13531-13535

van Oppen M (2001) In vitro establishment of symbiosis in Acropora millepora planulae. Coral Reefs 20:200

> Weis VM, Reynolds WS, deBoer MD, Krupp DA (2001) Hostsymbiont specificity during onset of symbiosis between the dinoflagellates Symbodinium spp. and planula larvae of the scleractinian coral Fungia scutaria. Coral Reefs 20: 301-308

> Wellington GM, Fitt WK (2003) Influence of UV radiation on the survival of larvae from broadcast-spawning reef corals. Mar Biol 143:1185-1192

Wick GA, Emery WJ, Kantha LH, Schlussel P (1996) The behavior of the bulk-skin sea surface temperature difference under varying wind speed and heat flux. J Phys Oceanogr 26:1969-1988

> Yakovleva IM, Baird AH (2005) Ontogenetic change in the abundance of mycosporine-like amino acids in non-zooxanthellate coral larvae. Coral Reefs 24:443-452

Yakovleva I, Bhagooli R, Takemura A, Hidaka M (2004) Differential susceptibility to oxidative stress of two scleractinian corals: antioxidant functioning of mycosporineglycine. Comp Biochem Physiol B Biochem Mol Biol 139: 721-730

Yellowlees D, Alwyn T, Rees V, Leggat W (2008) Metabolic interactions between algal symbionts and invertebrate hosts. Plant Cell Environ 31:679-694

Submitted: July 21, 2008; Accepted: November 24, 2008 Proofs received from author(s): March 6, 2009 